\title{
The Mechanism of Transpassive Dissolution of AISI 321 Stainless Steel in Sulphuric Acid Solution
}

\author{
A. Fattah-Alhosseini ${ }^{1}$ and N. Attarzadeh ${ }^{2}$ \\ ${ }^{1}$ Faculty of Engineering, Bu-Ali Sina University (BASU), Hamedan 65178-38695, Iran \\ ${ }^{2}$ Department of Materials Engineering, Isfahan University of Technology, Isfahan 84156-83111, Iran
}

Correspondence should be addressed to A. Fattah-Alhosseini, a.fattah@basu.ac.ir

Received 9 August 2010; Accepted 21 October 2010

Academic Editor: Angela Molina

Copyright ( 2011 A. Fattah-Alhosseini and N. Attarzadeh. This is an open access article distributed under the Creative Commons Attribution License, which permits unrestricted use, distribution, and reproduction in any medium, provided the original work is properly cited.

\begin{abstract}
The transpassive dissolution mechanism of AISI 321 stainless steel in a $0.5 \mathrm{M}$ sulphate solution was studied using electrochemical impedance spectroscopy (EIS). On the basis of the experimental results, surface charge approach, and point defect model, a kinetic model of the transpassive dissolution process is proposed. The transpassive film is modeled as a highly doped n-type semiconductor-insulator-p-type semiconductor structure. Injection of negative defects at the transpassive film/solution interface results in their accumulation as a negative surface charge. It alters the nonstationary transpassive film growth rate controlled by the transport of positive defects (oxygen vacancies). The model describes the process as dissolution of $\mathrm{Cr}$ as $\mathrm{Cr}$ (VI) and Fe as Fe (III) through the transpassive film via parallel reaction paths.
\end{abstract}

\section{Introduction}

Transpassivation is a phenomenon in which a passivated metal starts rapid dissolution if the electrode potential of the metal becomes too positive [1]. Transpassive dissolution of a metal or alloy can be defined as the formation of chemical species in a valence state higher than that in the primary passive film formed on the material [2-7]. Transpassive dissolution of a range of alloys is closely related to passive film breakdown and localized corrosion phenomena. It leads to a depletion of alloying elements such as $\mathrm{Cr}$ in the first atomic layers near the solution, which are the most susceptible to localized attack by aggressive anions [8-18]. Two main approaches can serve as a basis for a theoretical treatment of the problem.

The Surface Charge Approach (SCA). The SCA assumes that transpassive dissolution is a complex process including several reaction stages: formation and growth of a passive film via generation, transport and annihilation of ionic point defects, continuous changes in the stoichiometry of this film and especially of the first atomic layers adjacent to the solution, charge transfer reactions at the film/solution interface, and transport of reaction products in the bulk solution. According to this model the passive film was represented as an n-i-p junction structure with injection of oxygen vacancies from the metal substrate during film growth and metal vacancies from the solution during film dissolution. Assuming that the transport of metal vacancies is slower than the rate of their annihilation at the metal/film interface, they accumulate at the film/solution interface. This accumulation of negative charge enhances the nonstationary transport of positively charged oxygen vacancies, thus explaining the low frequency inductive loop in the impedance response of a range of passive metals [19-26].

The Point Defect Model (PDM). The PDM assumes segregation of alloying elements such as $\mathrm{Cr}$ in the film as high valency cations. These cations are assumed to reduce the concentration and diffusivity of cation vacancies in the film by means of forming complexes with them. Macdonald et al. assume that there is an accumulation of oxygen vacancies at the metal/film interface and a corresponding accumulation of cation vacancies at the film/solution interface [27-30]. 
As transpassivation is a rapid dissolution process, it is generally regarded as a type of corrosion damage to a passivated metal. How to prevent transpassivation is an important topic in corrosion science and engineering. In general, stainless steels are more widely used in many corrosive environments and are more likely to suffer from transpassivation damage. Therefore, it seems that an investigation into transpassivation mechanism of stainless steels will be of scientific and practical interest.

\section{Experimental}

Specimens were fabricated from $1 \mathrm{~cm}$ diameter rods of AISI 321 stainless steel; the nominal composition is given in the Table 1. The samples were placed in stainless steel sacks and were annealed to eliminate the cold work effect due to cutting process. The annealing was preformed at $1050^{\circ} \mathrm{C}$ for $90 \mathrm{~min}$ followed by water quenching. The working electrode pretreatment consisted of mechanical polishing on emery paper up to 1200 grade, degreasing and rinsing with distilled water. A three electrode cell featuring a Pt counter electrode and a calomel reference electrode was employed. The solution $\left(0.5 \mathrm{M} \mathrm{H}_{2} \mathrm{SO}_{4}\right)$ was prepared from analytical grade $97 \% \mathrm{H}_{2} \mathrm{SO}_{4}$ and distilled water.

All electrochemical measurements were performed using an EG\&G PAR Model 273A potentiostat/galvanostat controlled by a personal computer at ambient temperature (23$25^{\circ} \mathrm{C}$ ). A polarization curve was obtained at a potential scan rate of $1 \mathrm{mV} / \mathrm{s}$. To perform impedance measurements, the current versus time curve was recorded at each potential until a steady state current was reached. The impedance spectra were measured at this steady state in a frequency range of $10 \mathrm{mHz}-100 \mathrm{KHz}$ at an AC amplitude of $10 \mathrm{mV}$ (rms). The validation of the impedance spectra was performed by checking the linearity condition, that is, measuring spectra at AC signal amplitudes between 5 and $15 \mathrm{mV}$ (rms). For the simulation processing of the impedance data, Zview2 software was employed.

\section{Results and Discussion}

3.1. Polarization Behavior. The potentiodynamic polarization curve of AISI 321 stainless steel in $0.5 \mathrm{M} \mathrm{H}_{2} \mathrm{SO}_{4}$ solution is shown in Figure 1. According to Figure 1, two stages of the passive process can be distinguished in the curve. The low potential passive region ranges from about -0.15 to $0.3 \mathrm{~V}$ versus SCE (region I). In region II, the comparatively slow increase of the current in the potential range $0.3-0.9 \mathrm{~V}$ versus SCE could be connected to the formation of high valency $\mathrm{Cr}$ [31] in the film prior to transpassive dissolution. The steeper increase in the range from 0.9 to $1.1 \mathrm{~V}$ versus SCE (region III) is most probably related to the onset of the transpassive dissolution.

3.2. EIS Measurements. Typical experimental impedance spectra for the transpassive state on AISI 321 stainless steel are shown in Figure 2, in the form of Nyquist plots, in which the imaginary component of the impedance is plotted against

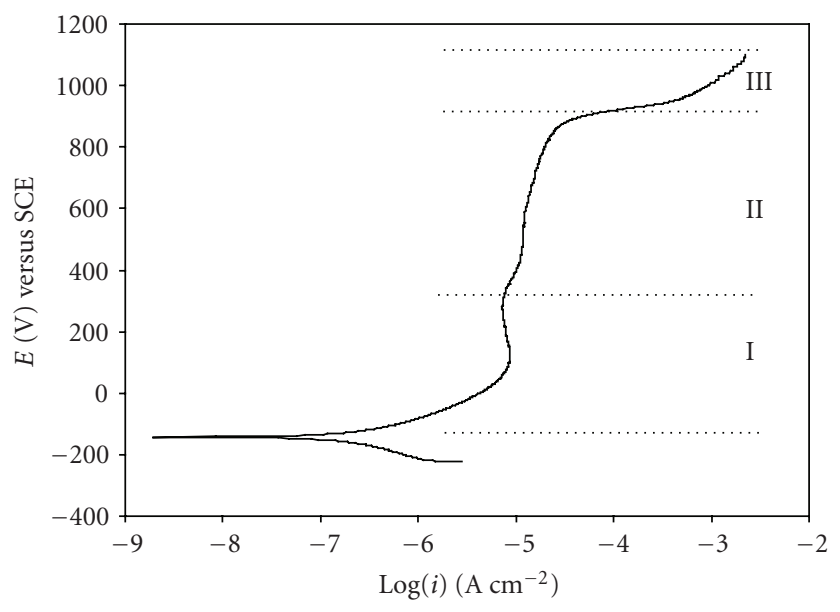

FIGURE 1: Potentiodynamic polarization curve for AISI 321 stainless steel in $0.5 \mathrm{M} \mathrm{H}_{2} \mathrm{SO}_{4}$. Potential regions: I-:low potential passive, II-:high potential passive, III-:transpassive dissolution.

the real component for decreasing frequencies. In all cases, the correlation between experimental data and simulated data is judged to be acceptable. Two time constants-a high frequency capacitive and a low frequency inductivefollowed by a capacitive behavior at the lowest frequencies are observed at $E \geq 1.0 \mathrm{~V}$ versus SCE. Thus, the high frequency capacitive loop reflects the high field assisted migration of defects in the transpassive film; the inductive loop at intermediate frequencies is due to the relaxation of the negative surface charge formed by the accumulation of cation vacancies at the transpassive film/solution interface and, at the lowest frequencies, the faradaic pseudocapacitance is detected.

Based on the polarization curve and the Nyquist plots, it is clear that the barrier layer in the transpassive region cannot exist since, as Macdonald mentioned, the current density is high. Therefore, the transpassive film must be a nonbarrier layer which has little resistance to current flow $[2,3]$.

In order to model the transpassive film with electrical analogs, the equivalent electrical circuit of Figure 3 was found to be appropriate $[32,33]$. In this circuit, CPE is the high frequency constant phase element of the metal/transpassive film/solution system, $R_{t}$ is the defect migration resistance, $R_{\mathrm{SC}}$ and $L_{\mathrm{SC}}$ are elements associated with the inductive loop observed throughout the investigated potential range, $C$ is the Faradaic pseudocapacitance, and $R_{S}$ is the uncompensated solution resistance. These parameter values characterize the properties of the interface and the rates of the reaction steps involved and they acquire clear physical meaning only when related to a specific kinetic model. The dependences of $R_{t}, R_{\mathrm{SC}}$, and $L_{\mathrm{SC}}$ on the potential are presented in Figures 4(a) and 4(b). According to Figures 4(a) and 4(b), a steep decrease of $R_{t}, R_{\mathrm{SC}}$, and $L_{S C}$ is observed in the transpassive dissolution region. A more detailed explanation of the circuit elements will be presented in the Section 3.3 on the basis of a kinetic model. 
TABLE 1: Nominal chemical composition of AISI 321 stainless steel.

\begin{tabular}{lccccccccccc}
\hline Elements & $\mathrm{Cr}$ & $\mathrm{Ni}$ & $\mathrm{Mn}$ & $\mathrm{Si}$ & $\mathrm{C}$ & $\mathrm{Ti}$ & $\mathrm{Nb}$ & $\mathrm{S}$ & $\mathrm{Mo}$ & $\mathrm{Cu}$ & $\mathrm{Fe}$ \\
\hline AISI 321/wt\% & 19.1 & 9.85 & 1.65 & 0.297 & 0.086 & 0.68 & 0.035 & 0.05 & 0.16 & 0.172 & $\mathrm{Bal}$ \\
\hline
\end{tabular}

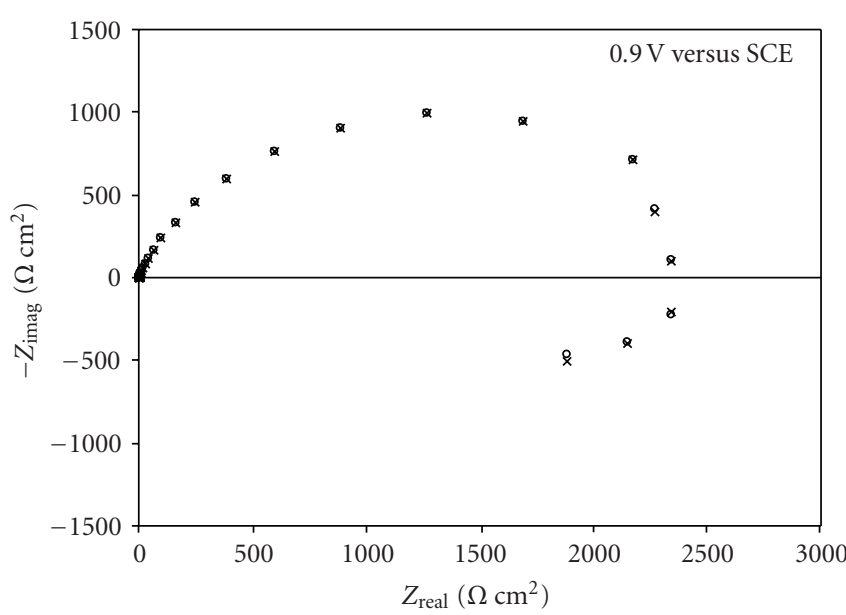

(a)

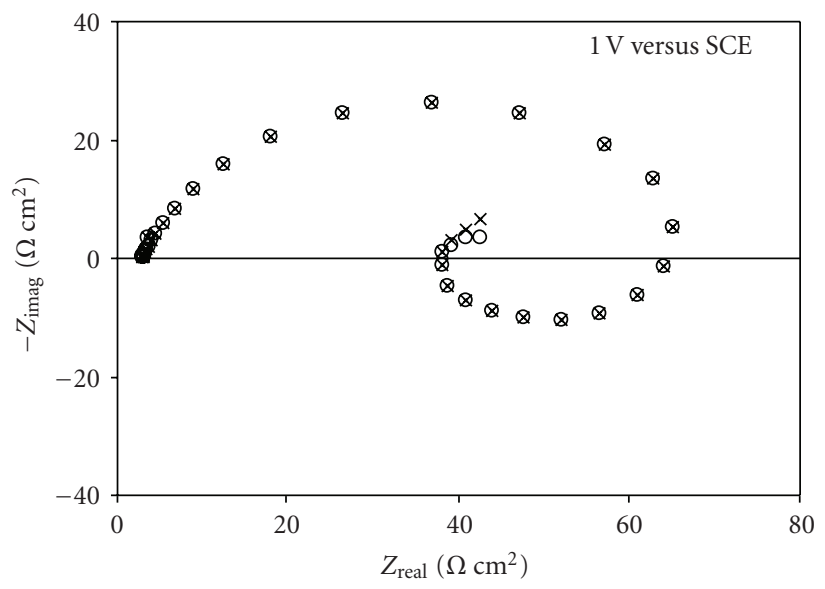

○ Experimental

$\times$ Simulated

(c)

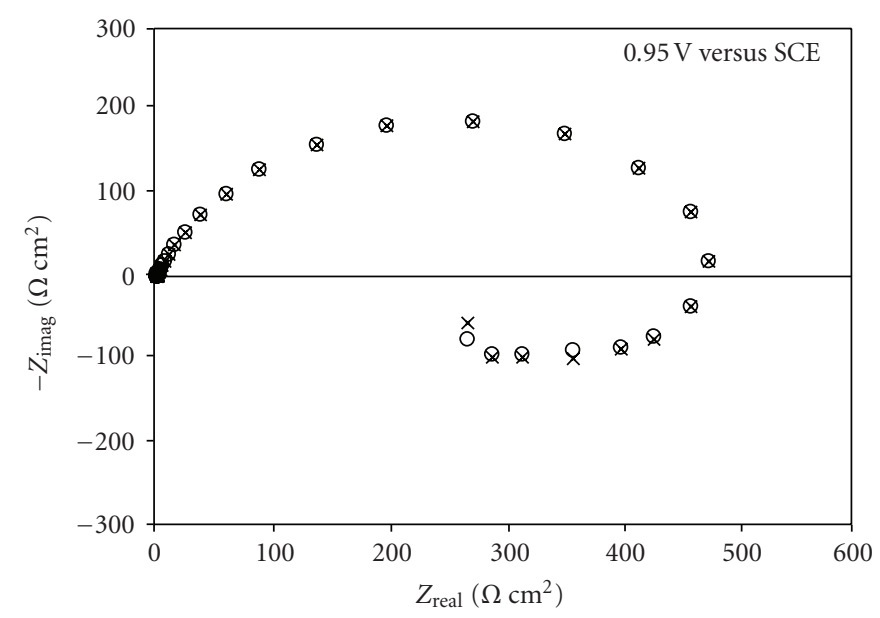

(b)

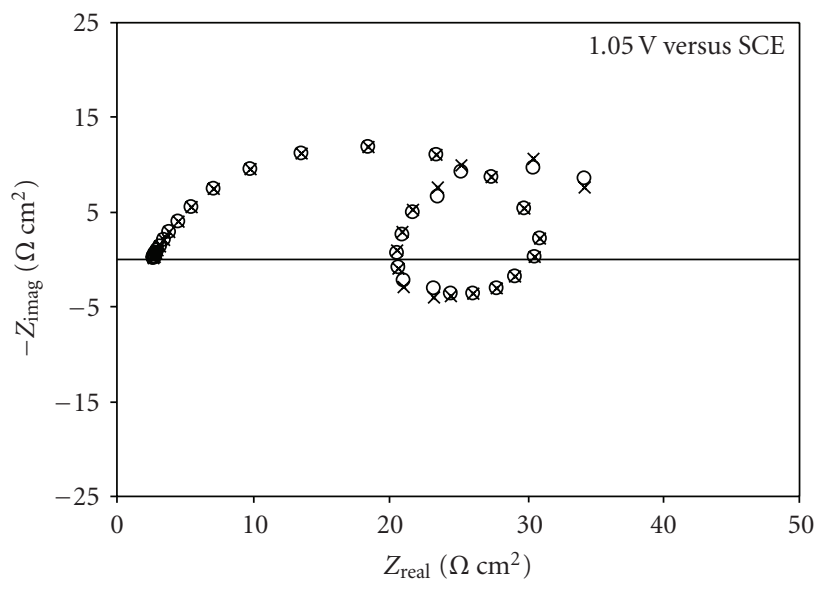

○ Experimental

$\times$ Simulated

(d)

FIGURE 2: Electrochemical impedance spectra for AISI 321 stainless steel in the transpassive region registered after 30-minute polarization at $0.8 \mathrm{~V}$ versus SCE.

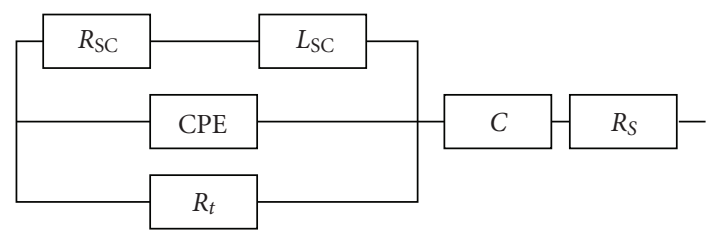

Figure 3: Equivalent electrical circuit of the metal/ transpassive film/solution interface.

3.3. A Kinetic Model Based on PDM and SCA. Figure 5 summarizes the physicochemical processes that are envisioned to occur within the transpassive film formed on the AISI 321 stainless steel, according to the PDM [34-39].
This model provides microscopic description of the growth and breakdown of the passive film under steady state and transient condition. PDM is based on the migration of the point defects under the influence of the electrostatic field in the film [2-6]. On the basis of PDM for a given potential at steady state, the continuity equation imposes [7-11]:

$$
i_{s s}=i_{m / f}=i_{f}=i_{f / s} .
$$

Therefore, the impedance of the system will be the sum of the impedances of the two interfaces and the transpassive film [7-11]

$$
Z=Z_{m / f}+Z_{f}+Z_{f / s}
$$




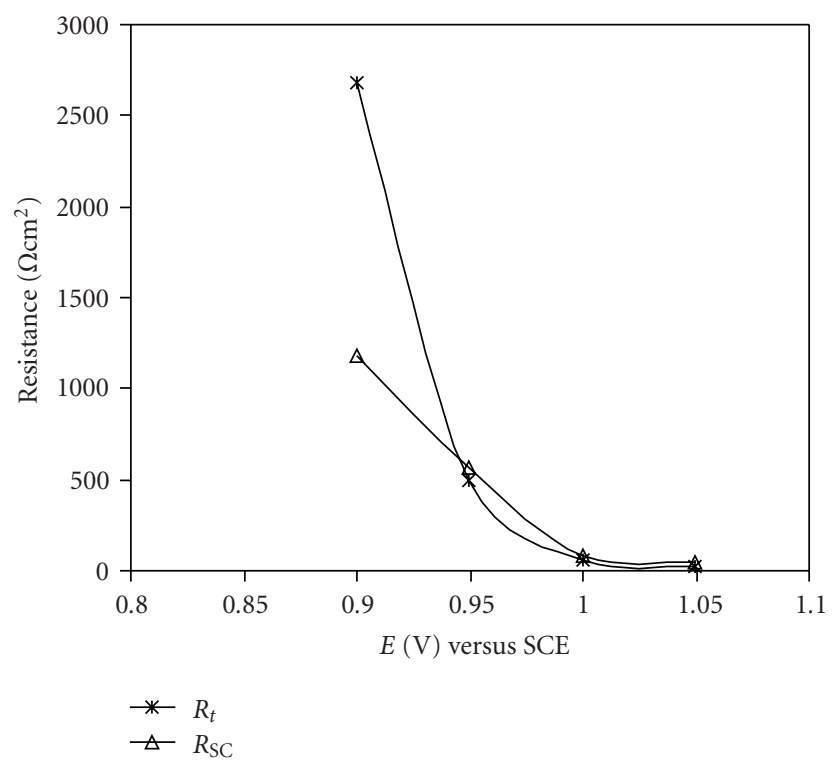

(a)

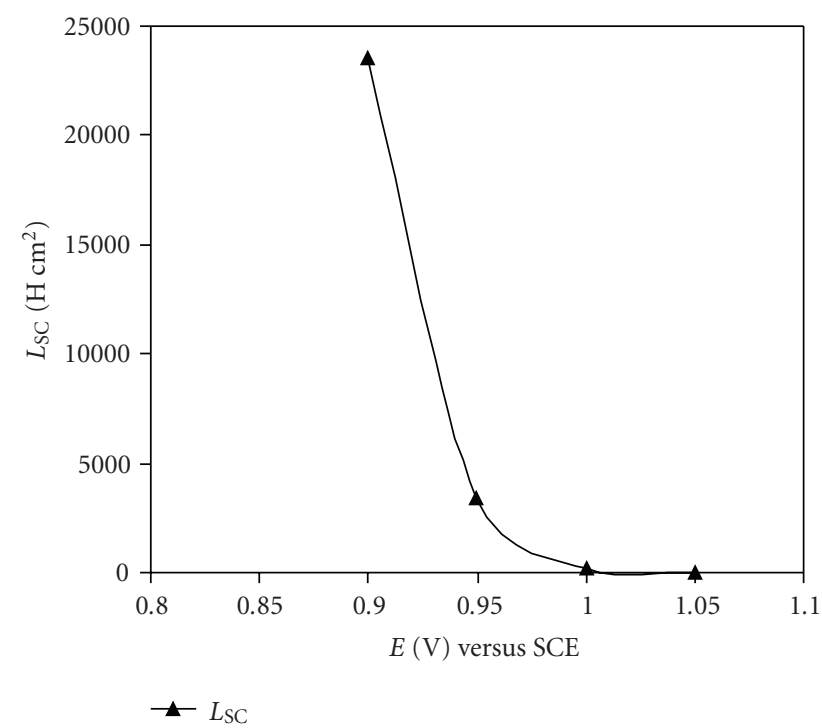

(b)

Figure 4: Potential dependences of (a) $R_{t}$ and $R_{\mathrm{SC}}$, (b) $L_{\mathrm{SC}}$. These circuit elements are acquired from equivalent electrical circuit of Figure 3.

According to the PDM [34-45] at the metal/transpassive film interface, annihilation of metal vacancies and injection of oxygen vacancies take place as follows:

$$
\begin{aligned}
& \mathrm{M} \stackrel{r_{1}}{\rightarrow} \mathrm{M}_{\mathrm{M}}+\frac{3}{2} \mathrm{~V}_{\mathrm{O}}^{2+}+3 \overline{\mathrm{e}}, \\
& \mathrm{M}+\mathrm{V}_{\mathrm{M}}^{3-} \stackrel{r_{2}}{\rightarrow} \mathrm{M}_{\mathrm{M}}+3 \overline{\mathrm{e}} .
\end{aligned}
$$

The interfacial rate constants are assumed to be potential dependent in a tafel manner

$$
r_{x}=r_{x}^{0} \exp \left(\beta_{x} \Phi_{m / f}\right)
$$

Then the balance of fluxes at the interface gives $[19,20]$

$$
i_{m / f}=F\left[r_{2} C_{\mathrm{V}_{\mathrm{M}}^{3-}}^{\prime \prime}+r_{1}\right]
$$

Based upon the SCA [20], the small sine perturbation does not lead to a significant deviation of $C_{\mathrm{V}_{\mathrm{M}}^{3-}}^{\prime \prime}$ from its steady state value. Therefore, the impedance at the metal/transpassive film interface is

$$
\begin{aligned}
& Z_{m / f}^{-1}=R_{m / f}^{-1}+j \omega C_{m / f}, \\
& R_{m / f}^{-1}=F\left[\beta_{1} r_{1} C_{\mathrm{V}_{\mathrm{M}}^{3-}}^{\prime \prime}+\frac{3}{2} \beta_{2} r_{2}\right] .
\end{aligned}
$$

According to the SCA $[19,20]$ in the transpassive film with a thickness $L$, oxygen vacancy motion is driven by the electric field at the metal/transpassive film interface:

$i_{f}=$

$$
\left(\frac{2 F D_{\mathrm{V}_{\mathrm{O}}^{2+}}}{2 a}\right)\left[C_{\mathrm{V}_{\mathrm{O}}^{2+}}^{\prime \prime}-C_{\mathrm{V}_{\mathrm{O}}^{2+}}^{\prime} \exp \left(-\frac{L}{a}\right)\right] \times \exp \left[\frac{(2 F a / R T) \Phi_{\mathrm{V}_{\mathrm{O}}^{2+}}}{L}\right]
$$

where [43-45]

$$
\begin{gathered}
\Phi_{\mathrm{V}_{\mathrm{O}}^{2+}}=\Phi_{m / f}+\Phi_{f}+\Phi_{f / s}=E_{a} \\
\Phi_{m / f}=(1-\alpha) E_{a}-E_{a} L \\
\Phi_{f}=E_{a} L \\
\Phi_{f / s}=\frac{q L}{\varepsilon \varepsilon_{0}}
\end{gathered}
$$

and $q$ is a negative surface charge accumulated at the transpassive film/solution interface by the cation vacancies generated mainly by the transpassive dissolution reaction $[19,20]$. As for most cases, $L \gg a, C_{\mathrm{V}_{O}^{2+}}^{\prime \prime} \gg C_{\mathrm{V}_{O}^{2+}}^{\prime} \exp (-L / a)$, and

$i_{f}=\left(\frac{2 F D_{\mathrm{V}_{\mathrm{O}}^{2+}}}{2 a}\right) C_{\mathrm{V}_{\mathrm{O}}^{2+}}^{\prime \prime} \exp \left[\left[\frac{2 F a}{R T}\right] \times \frac{\left[(1-\alpha) E_{a}+q L_{f / s} / \varepsilon \varepsilon_{0}\right]}{L}\right] ;$

by setting $A=\left(2 F D_{\mathrm{V}_{\mathrm{O}}^{2+}} / 2 a\right) C_{\mathrm{V}_{\mathrm{O}}^{2+}}^{\prime \prime}$ and $B=(2 F a / R T)$,

$$
i_{f}=A \exp \left\lfloor B \times \frac{\left[(1-\alpha) E_{a}+q L_{f / s} / \varepsilon \varepsilon_{0}\right]}{L}\right\rfloor .
$$

The time dependence of the surface charge is treated in analogy to the SCA $[19,20]$ :

$$
\frac{d q}{d t}=i_{s s} S\left(q_{s}-q\right)
$$

where $S$ is a capture cross section for a positive defect by the negative surface charge. The steady-state value of the surface charge is

$$
q_{s}=\Phi_{f / s} C_{f / s}=\frac{\alpha E_{a} \varepsilon \varepsilon_{0}}{L_{f / s}}
$$




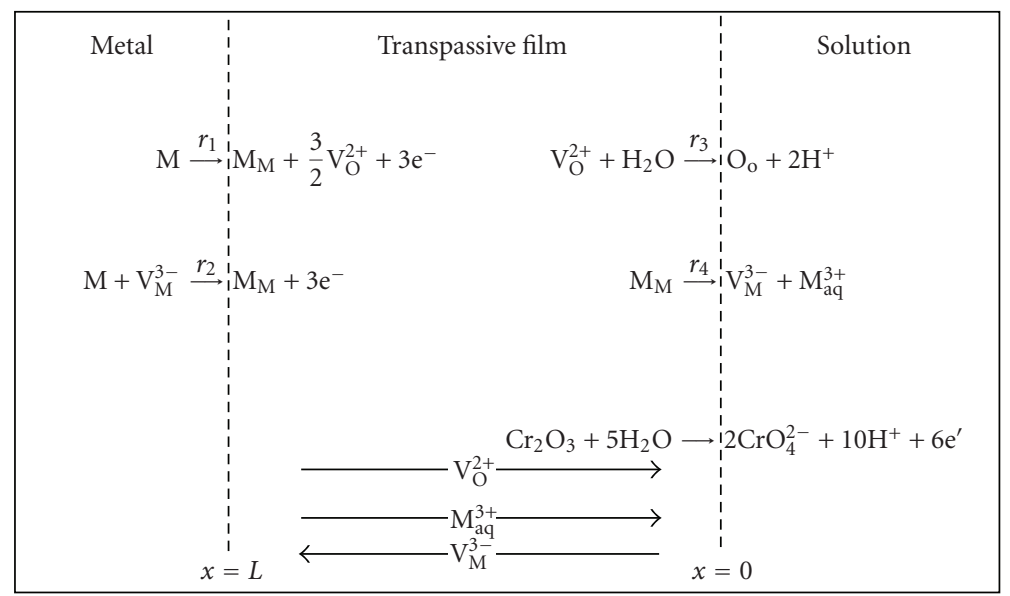

FIGURE 5: A Scheme representation of the processes in the metal/transpassive film/solution system, according to PDM.

Inserting this in (11) results in the expression $[19,20]$

$$
\frac{d q}{d t}=i_{s s} S\left(\frac{\alpha E_{a} \varepsilon \varepsilon_{0}}{L_{f / s}}-q\right)
$$

From (10) and (13) under a small amplitude AC perturbation,

$$
\begin{aligned}
& \Delta i=i_{s s} B\left\lfloor\frac{\left[(1-\alpha) \Delta E_{a}+\Delta q L_{f / s} / \varepsilon \varepsilon_{0}\right]}{L}\right], \\
& \Delta q=\frac{i_{s s} S \alpha \Delta E_{a} \varepsilon \varepsilon_{0}}{\left\lfloor L_{f / s}\left(j \omega+i_{s s} S\right)\right]} .
\end{aligned}
$$

Accordingly, the faradaic impedance of the transpassive film is

$$
Z_{f}^{-1}=\frac{\Delta i}{\Delta E_{a}}=\frac{i_{s s} B\left[\left[(1-\alpha)+i_{s s} S \alpha \varepsilon \varepsilon_{0}\right] / j \omega+i_{s s} S\right]}{L}
$$

which is equivalent to

$$
Z_{f}^{-1}=R_{t}^{-1}+\left(j \omega L_{\mathrm{SC}}+R_{\mathrm{SC}}\right)^{-1}
$$

where $[19,20]$

$$
\begin{gathered}
R_{t}=\frac{L}{i_{s S} B(1-\alpha)}, \\
L_{S C}=\frac{L}{i_{s s}^{2} B S \alpha}, \\
R_{S C}=\frac{L}{i_{s S} B \alpha} .
\end{gathered}
$$

In order to derive the total impedance, the high frequency constant phase element of the transpassive film and the faradaic pseudocapacitance has to be added in the appropriate manner. Thus, the experimental impedance spectra are well described and will be discussed according to the following transfer function [33]:

$$
Z_{f}^{-1}=\left[R_{t}^{-1}+\left(j \omega L_{\mathrm{SC}}+R_{\mathrm{SC}}\right)^{-1}+j \omega C\right]^{-1}+\left(\frac{1}{Y_{0}}\right)(j \omega)^{-n}
$$

According to the PDM [34-45] at the transpassive film/ solution interface, reaction of oxygen vacancies with water and production of metal vacancies take place as follows:

$$
\begin{gathered}
\mathrm{V}_{\mathrm{O}}^{2+}+\mathrm{H}_{2} \mathrm{O} \stackrel{r_{3}}{\rightarrow} \mathrm{O}_{\mathrm{o}}+2 \mathrm{H}^{+} \\
\mathrm{M}_{\mathrm{M}} \stackrel{r_{4}}{\rightarrow} \mathrm{V}_{\mathrm{M}}^{3-}+\mathrm{M}_{\mathrm{aq}}^{3+} .
\end{gathered}
$$

At higher potentials, passivity is observed to break down on many metals and alloys, and the dissolution rate of the substrate increases dramatically as the system transitions into the transpassive state. This process is postulated to be due to the oxidative dissolution of the barrier layer; for example, in the case of stainless steels, which form chromic oxide barrier layers, the onset of transpassive dissolution is due to the reaction $[2,3]$

$$
\mathrm{Cr}_{2} \mathrm{O}_{3}+5 \mathrm{H}_{2} \mathrm{O} \rightarrow 2 \mathrm{CrO}_{4}^{2-}+10 \mathrm{H}^{+}+6 \mathrm{e}^{\prime} .
$$

It is noticed that transpassive film on the stainless steels in the transpassive region are assumed to be covered by a mixed Cr (VI) and Fe (III) oxide film and some Mocontaining species. Also it is assumed [46-49] that the amount of $\mathrm{Ni}$ in the transpassive film on stainless steels is negligible, and no separate reaction path for the dissolution of Mo from the transpassive film as Mo (VI) is included in the present approach. Rather, it is assumed that Mo in the alloy substrate has a catalytic effect on the transpassive dissolution of $\mathrm{Cr}$ via the formation of soluble molybdate or Cr-Mo-containing species that accelerate the abstraction of $\mathrm{Cr}$ (VI) from the outermost layer of the transpassive film [12]. Therefore, the transpassive dissolution reaction results in an accumulation of cation vacancies near the transpassive 
film/solution interface in a layer with a thickness $L_{f / s}$ and to a depletion of this layer in $\mathrm{Cr}$ positions in the transpassive film. The balance of fluxes at the transpassive film/solution interface gives $[19,20]$

$$
i_{f / s}=6 r_{5} F \exp \left(\frac{3 F \alpha \alpha_{5} E_{a}}{R T}\right)+r_{3} C_{\mathrm{V}_{\mathrm{O}}^{2+}}^{\prime}+r_{4}
$$

Assuming that the small sine perturbation does not change significantly $C_{\mathrm{V}_{\mathrm{O}}^{2+}}^{\prime}$, the impedance of that interface becomes

$$
Z_{f / s}^{1-}=R_{f / s}^{1-}+j \omega C_{f / s}
$$

The impedance response of the system in the transpassive dissolution exhibits only two time constants (one capacitive and one inductive) and a series capacitive features at low frequencies, which is consistent with the impedance defined by (16)-(20). In order to explore these dependences within the frames of the present model, the transpassive film thickness versus potential relationship is taken from the PDM [6] with the assumption that the applied potential is expressed versus the potential of zero film thickness:

$$
L=\frac{\left(1-\alpha-\alpha \alpha_{5}(\chi / \delta-1) / \alpha_{1}\right) E_{a}}{E} .
$$

In transpassive dissolution $\delta=3$ and $\chi=6$,

$$
L=\frac{\left(1-\alpha-\alpha \alpha_{5} / \alpha_{1}\right) E_{a}}{E}
$$

Inserting (26) in (16)-(18), it follows that

$$
\begin{aligned}
& R_{t}=\frac{\left(1-\alpha-\alpha \alpha_{5} / \alpha_{1}\right) E_{a}}{\left(E i_{s s} B(1-\alpha)\right)}, \\
& L_{\mathrm{SC}}=\frac{\left(1-\alpha-\alpha \alpha_{5} / \alpha_{1}\right) E_{a}}{\left(E i_{s s}^{2} B S \alpha\right)}, \\
& R_{\mathrm{SC}}=\frac{\left(1-\alpha-\alpha \alpha_{5} / \alpha_{1}\right) E_{a}}{\left(E i_{s s} B \alpha\right)} .
\end{aligned}
$$

The numerators of (28) increase linearly with the potential whereas their denominators increase exponentially with the same parameter. Thus $R_{t}, R_{\mathrm{sc}}$, and $L_{\mathrm{sc}}$ all decrease which is found experimentally in Figures $4(\mathrm{a})$ and $4(\mathrm{~b})$. From (28)-(36), two important characteristics of the system could be derived, namely [19],

$$
\begin{aligned}
& \alpha=\frac{\left(R_{t} / R_{\mathrm{SC}}\right)}{\left[1+\left(R_{t} / R_{\mathrm{SC}}\right)\right]}, \\
& S=\frac{L_{\mathrm{SC}} i_{S S}}{R_{\mathrm{SC}}} .
\end{aligned}
$$

$\alpha$ and $S$ versus the transpassive potential are plotted in Figures 6 and 7. The obtained dependences are consistent with the physical picture given in Figure 5. Due to the accumulation of $\mathrm{CrO}_{4}^{2-}$ at the transpassive film/solution interface and the simultaneous $\mathrm{Cr}$ depletion of the interface [50], the rate of the transpassive dissolution is slowed down. This leads to a gradual dissipation of the surface charge $q$.

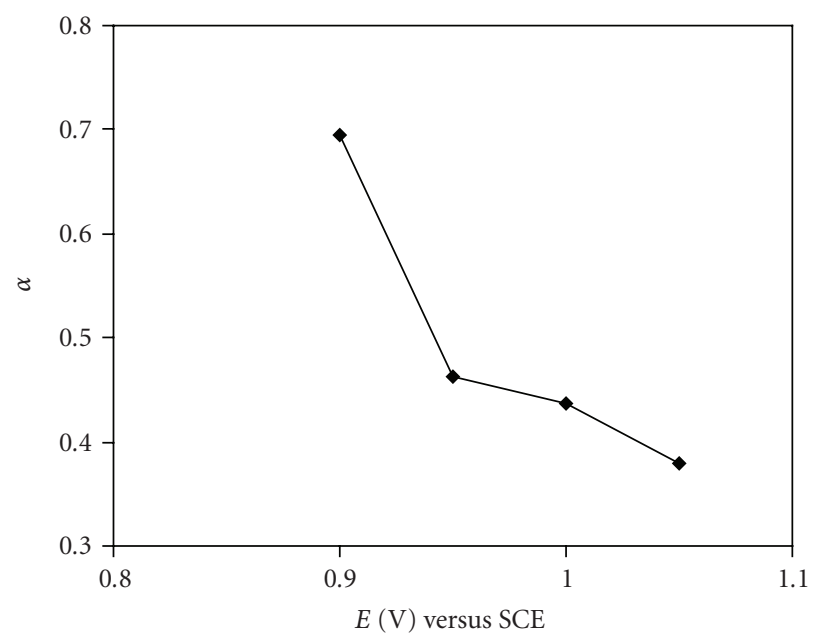

Figure 6: Potential dependences of the polarizability of the transpassive film/solution interface. This parameter is acquired from (29).

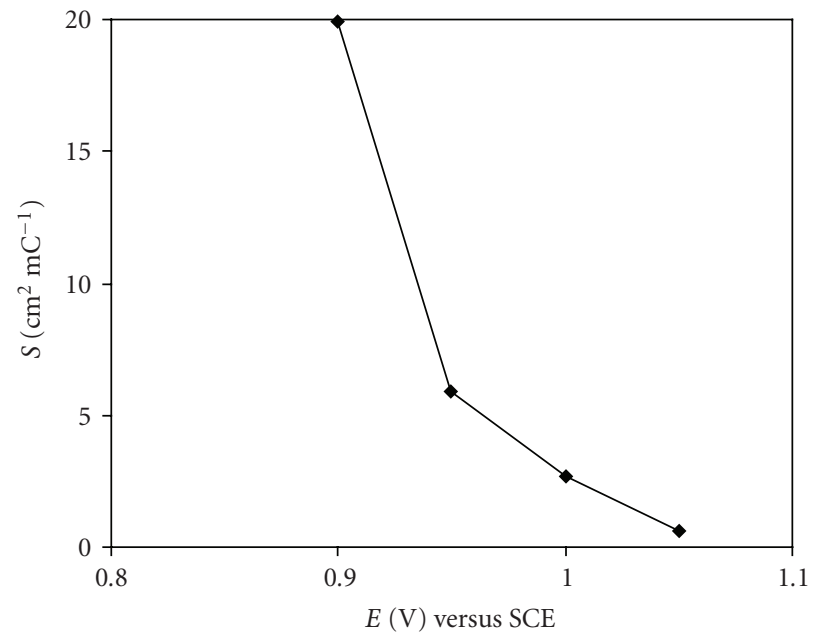

Figure 7: Potential dependences of the capture cross section per positive defect. This parameter is acquired from (29).

As a consequence, the parameter $\alpha$ characterizing the part of the applied potential consumed at the transpassive film/solution interface decreases (Figure 6). Similar speculations could explain the potential trend of the capture cross section per charge carrier $S$ (Figure 7). This quantity is related to the surface excess of negative carriers by the following equation [20]:

$$
S=(2 F \varsigma)^{1-} .
$$

The observed decrease of $S$ (Figure 7 ) is caused by the increase of the surface excess of negative carriers $\varsigma$ due to the gradual dissipation of the surface charge.

\section{Conclusions}

This study reports an EIS study of transpassive dissolution of AISI 321 stainless steel in $0.5 \mathrm{M} \mathrm{H}_{2} \mathrm{SO}_{4}$ solution. The overall 
impedance of the system was described using the electrical equivalent circuit, Figure 3, and by the corresponding transfer function, (22). Based on the Nyquist plots and the polarization curve, it is clear that the transpassive film must be a nonbarrier layer which has little resistance to current flow. On the basis of the experimental results, SCA, and PDM, a generalized model of the transpassivity is proposed. This model represents the transpassive film as a highly doped n-i-p junction structure. Injection of negative defects at the transpassive film/solution interface results in their accumulation as a negative surface charge. It alters the nonstationary transpassive film growth rate controlled by the transport of positively charge defects. On the basis of the results obtained, a kinetic model including the dissolution of $\mathrm{Cr}$ from the outermost cation layer of the transpassive film in parallel reaction paths is deduced.

\section{Nomenclature}

$a$ : Atomic jump distance, $\mathrm{cm}$

$\alpha: \quad$ Polarizability of the transpassive film/solution interface

A: Constant in the high field migration equation, $\mathrm{Acm}^{-2}$

$B$ : Field coefficient in the high field equation, $\mathrm{V}^{-1} \mathrm{~cm}$

$\beta_{x}$ : Tafel coefficients of the interfacial reactions $(x=1-5), \mathrm{V}^{-1}$

$C_{\mathrm{V}_{0}^{2+}}^{\prime}$ : Concentration of oxygen vacancies at the transpassive film/solution interface, mol $\mathrm{cm}^{-3}$

$C_{\mathrm{V}_{\mathrm{O}}^{2}}^{\prime \prime}$ : Concentration of oxygen vacancies at the metal/transpassive film interface, $\mathrm{mol} \mathrm{cm}{ }^{-3}$

$\mathrm{C}_{\mathrm{V}_{\mathrm{M}}^{3}}^{\prime}$ : Concentration of metal vacancies at the transpassive film/solution interface, mol $\mathrm{cm}^{-3}$

$\mathrm{C}_{\mathrm{V}_{\mathrm{M}}^{3-}}^{\prime \prime}$ : Concentration of metal vacancies at the metal/transpassive film interface, $\mathrm{mol} \mathrm{cm}^{-3}$

$D_{\mathrm{V}_{\mathrm{O}}^{2+}}$ : Diffusivity of oxygen vacancies, $\mathrm{cm}^{2} \mathrm{~s}^{-1}$

$E_{a}$ : Applied potential, $\mathrm{V}$

E: $\quad$ Electric field strength, $\mathrm{Vcm}^{-1}$

$i_{\mathrm{m} / \mathrm{f}}$ : Current density at the metal/transpassive film interface, $\mathrm{Acm}^{-2}$

$i_{\mathrm{f}}: \quad$ Film formation current density, $\mathrm{Acm}^{-2}$

$i_{\mathrm{f} / \mathrm{s}}: \quad$ Current density at the transpassive film/solution interface, $\mathrm{Acm}^{-2}$

$i_{s s}$ : Steady state current density, $\mathrm{Acm}^{-2}$

$j$ : $\quad$ Imaginary unit

$L: \quad$ Thickness of the transpassive film, $\mathrm{cm}$

$L_{\mathrm{f} / \mathrm{s}}$ : Thickness of the metal vacancy accumulation layer, $\mathrm{cm}$

M: $\quad$ Metal atom in the metal phase

$\mathrm{M}_{\mathrm{M}}$ : Metal position in the transpassive film

$\mathrm{O}_{\mathrm{o}}$ : Oxygen position in the transpassive film

$q$ : Negative surface charge at the transpassive film/solution interface, $\mathrm{C} \mathrm{cm}^{-2}$

$R_{t}$ : Charge transfer resistance, $\Omega \mathrm{cm}^{2}$

$R_{S}$ : Uncompensated solution resistance, $\Omega \mathrm{cm}^{2}$ $r_{x}$ : Rate constants of the interfacial reactions $(x=1-5) \mathrm{mol} \mathrm{cm}^{-2} \mathrm{~s}^{-1}$

S: Capture cross section for a positive defect, $\mathrm{cm}^{2} \mathrm{C}^{-1}$

$\mathrm{V}_{\mathrm{m}}$ : Molar volume of the phase in the transpassive film, $\mathrm{cm}^{3} \mathrm{~mol}^{-1}$

$\mathrm{V}_{\mathrm{O}}^{2+}$ : Oxygen vacancy in the transpassive film

$\mathrm{V}_{\mathrm{M}}^{3-}$ : Metal vacancy in the transpassive film

$Z_{m / f}:$ Impedance of the metal/transpassive film interface, $\Omega \mathrm{cm}^{2}$

$Z_{f}:$ Impedance of the transpassive film, $\Omega \mathrm{cm}^{2}$

$Z_{f / s}:$ Impedance of the transpassive film/solution interface, $\Omega \mathrm{cm}^{2}$

$\varsigma: \quad$ Maximum surface excess, $\mathrm{mol} \mathrm{cm}^{-2}$

$\varepsilon: \quad$ Dielectric constant of the transpassive film

$\varepsilon_{0}:$ Dielectric permittivity of vacuum

$\Phi_{m / f}$ : Local potential drop at the metal/transpassive film interface, $\mathrm{V}$

$\Phi_{f / s}$ : Local potential drop at the transpassive film/solution interface, $\mathrm{V}$

$\chi$ : $\quad$ Valency of transpassive dissolution

$\delta: \quad$ Valency of the cation in the transpassive film.

\section{References}

[1] G. Song, "Transpassivation of Fe-Cr-Ni stainless steels," Corrosion Science, vol. 47, no. 8, pp. 1953-1987, 2005.

[2] D. D. Macdonald, "On the tenuous nature of passivity and its role in the isolation of HLNW," Journal of Nuclear Materials, vol. 379, no. 1-3, pp. 24-32, 2008.

[3] D. D. MacDonald, "On the existence of our metals-based civilization I. Phase-space analysis," Journal of the Electrochemical Society, vol. 153, no. 7, pp. B213-B224, 2006.

[4] L. Zhang and D. D. Macdonald, "Segregation of alloying elements in passive systems-II. Numerical simulation," Electrochimica Acta, vol. 43, no. 18, pp. 2673-2685, 1998.

[5] D. D. Macdonald and M. Urquidi-Macdonald, "Theory of steady-state passive films," Journal of the Electrochemical Society, vol. 137, no. 8, pp. 2395-2402, 1990.

[6] D. D. Macdonald, "Point defect model for the passive state," Journal of the Electrochemical Society, vol. 139, no. 12, pp. 3434-3449, 1992.

[7] J. H. W. de Wit and H. J. W. Lenderink, "Electrochemical impedance spectroscopy as a tool to obtain mechanistic information on the passive behaviour of aluminium," Electrochimica Acta, vol. 41, no. 7-8, pp. 1111-1119, 1996.

[8] M. Bojinov, G. Fabricius, P. Kinnunen et al., "Mechanism of transpassive dissolution of Ni-Cr alloys in sulphate solutions," Electrochimica Acta, vol. 45, no. 17, pp. 2791-2802, 2000.

[9] M. Bojinov, G. Fabricius, T. Laitinen, and T. Saario, "Transpassivity mechanism of iron-chromium-molybdenum alloys studied by AC impedance, DC resistance and RRDE measurements," Electrochimica Acta, vol. 44, no. 24, pp. 43314343, 1999.

[10] M. Bojinov, I. Betova, and R. Raicheff, "A model for the transpassivity of molybdenum in acidic sulphate solutions based on ac impedance measurements," Electrochimica Acta, vol. 41, no. 7-8, pp. 1173-1179, 1996.

[11] M. Bojinov, G. Fabricius, T. Laitinen, and T. Saario, "The mechanism of the transpassive dissolution of chromium in 
acidic sulfate solutions," Journal of the Electrochemical Society, vol. 145, no. 6, pp. 2043-2050, 1998.

[12] I. Betova, M. Bojinov, T. Laitinen, K. Mäkelä, P. Pohjanne, and T. Saario, "The transpassive dissolution mechanism of highly alloyed stainless steels I. Experimental results and modelling procedure," Corrosion Science, vol. 44, no. 12, pp. 2675-2697, 2002.

[13] I. Betova, M. Bojinov, T. Laitinen, K. Mäkelä, P. Pohjanne, and T. Saario, "The transpassive dissolution mechanism of highly alloyed stainless steels II. Effect of $\mathrm{pH}$ and solution anion on the kinetics," Corrosion Science, vol. 44, no. 12, pp. 2699-2723, 2002.

[14] T. Piao and S.-M. Park, "Spectroelectrochemical studies of passivation and transpassive breakdown reactions of stainless steel," Journal of the Electrochemical Society, vol. 144, no. 10, pp. 3371-3377, 1997.

[15] M. Itagaki, A. Matsuzaki, and K. Watanabe, "The electrochemical impedance response of transpassive dissolution of chromium in neutral solutions containing sodium chloride and sodium fluoride," Corrosion Science, vol. 37, no. 11, pp. 1867-1878, 1995.

[16] R. Knoedler and K. E. Heusler, "The mechanism of oxidation of chromium to chromate," Electrochimica Acta, vol. 17, no. 2, pp. 197-212, 1972.

[17] M. S. El-Basiouny and S. Haruyama, "The polarization behaviour of chromium in acidic sulphate solutions," Corrosion Science, vol. 17, no. 5, pp. 405-414, 1977.

[18] N. Sato, "An overview on the passivity of metals," Corrosion Science, vol. 31, pp. 1-19, 1990.

[19] M. Bojinov, "The ability of a surface charge approach to describe barrier film growth on tungsten in acidic solutions," Electrochimica Acta, vol. 42, no. 23-24, pp. 3489-3498, 1997.

[20] M. Bojinov, I. Betova, G. Fabricius, T. Laitinen, R. Raicheff, and T. Saario, "The stability of the passive state of ironchromium alloys in sulphuric acid solution," Corrosion Science, vol. 41, no. 8, pp. 1557-1584, 1999.

[21] M. Bojinov, I. Betova, and R. Raicheff, "Transpassivity of molybdenum in $\mathrm{H}_{2} \mathrm{SO}_{4}$ solution," Journal of Electroanalytical Chemistry, vol. 381, no. 1-2, pp. 123-131, 1995.

[22] M. Bojinov, I. Betova, and R. Raicheff, "Influence of pH on the anodic dissolution mechanism of Fe-Mo alloys in sulphate solutions," Electrochimica Acta, vol. 44, no. 5, pp. 721-734, 1998.

[23] I. Betova, M. Bojinov, and TZ. Tzvetkoff, "Transpassive dissolution mechanism of ferrous alloys in phosphoric acid/acetic acid mixtures," Journal of Solid State Electrochemistry, vol. 9, no. 3, pp. 154-167, 2005.

[24] M. Bojinov, I. Betova, and R. Raicheff, "Influence of molybdenum on the anodic dissolution of iron in acidic solutions," Journal of Applied Electrochemistry, vol. 26, no. 9, pp. 939-946, 1996.

[25] I. Betova, M. Bojinov, P. Kinnunen, T. Laitinen, P. Pohjanne, and T. Saario, "Mechanism of transpassive dissolution of nickel-based alloys studied by impedance spectroscopy and rotating ring-disc voltammetry," Electrochimica Acta, vol. 47, no. 13-14, pp. 2093-2107, 2002.

[26] I. Betova, M. Bojinov, P. Kinnunen et al., "Transpassive dissolution mechanism of Ni-based alloys in a simulated bleaching solution: Effect of alloying elements," Journal of the Electrochemical Society, vol. 149, no. 11, pp. B499-B509, 2002.

[27] D. D. Macdonald, "Passivity-the key to our metals-based civilization," Pure and Applied Chemistry, vol. 71, no. 6, pp. 951-978, 1999.
[28] L. Zhang and D. D. Macdonald, "Segregation of alloying elements in passive systems-II. Numerical simulation," Electrochimica Acta, vol. 43, no. 18, pp. 2673-2685, 1998.

[29] A. Fattah-Alhosseini, M. A. Golozar, A. Saatchi, and K. Raeissi, "Effect of solution concentration on semiconducting properties of passive films formed on austenitic stainless steels," Corrosion Science, vol. 52, p. 205, 2010.

[30] A. Fattah-Alhosseini, A. Saatchi, M. A. Golozar, and K. Raeissi, "The passivity of AISI 316L stainless steel in $0.05 \mathrm{M} \mathrm{H}_{2} \mathrm{SO}_{4}$," Journal of Applied Electrochemistry, vol. 40, pp. 457-461, 2010.

[31] J. A. Bardwell, G. I. Sproule, B. MacDougall, M. J. Graham, A. J. Davenport, and H. S. Isaacs, "In situ XANES detection of $\mathrm{Cr}(\mathrm{VI})$ in the passive film on $\mathrm{Fe}-26 \mathrm{Cr}$," Journal of the Electrochemical Society, vol. 139, no. 2, pp. 371-373, 1992.

[32] G. Vázquez and I. González, "Diffusivity of anion vacancies in WO3 passive films," Electrochimica Acta, vol. 52, no. 24, pp. 6771-6777, 2007.

[33] M. Metikoš-Huković and Z. Grubač, "The growth kinetics of thin anodic $\mathrm{WO}_{3}$ films investigated by electrochemical impedance spectroscopy," Journal of Electroanalytical Chemistry, vol. 556, pp. 167-178, 2003.

[34] D. D. Macdonald, K. M. Ismail, and E. Sikora, "Characterization of the passive state on zinc," Journal of the Electrochemical Society, vol. 145, no. 9, pp. 3141-3149, 1998.

[35] D. D. MacDonald and A. Sun, "An electrochemical impedance spectroscopic study of the passive state on Alloy-22," Electrochimica Acta, vol. 51, no. 8-9, pp. 1767-1779, 2006.

[36] D. D. Macdonald, A. Sun, N. Priyantha, and P. Jayaweera, "An electrochemical impedance study of Alloy-22 in $\mathrm{NaCl}$ brine at elevated temperature: II. Reaction mechanism analysis," Journal of Electroanalytical Chemistry, vol. 572, no. 2, pp. 421$431,2004$.

[37] E. Sikora, J. Sikora, and D. D. Macdonald, "A new method for estimating the diffusivities of vacancies in passive films," Electrochimica Acta, vol. 41, no. 6, pp. 783-789, 1996.

[38] Z. Lu and D. D. Macdonald, "Transient growth and thinning of the barrier oxide layer on iron measured by real-time spectroscopic ellipsometry," Electrochimica Acta, vol. 53, no. 26, pp. 7696-7702, 2008.

[39] D. D. Macdonald, E. Sikora, and J. Sikora, "The kinetics of growth of the passive film on tungsten in acidic phosphate solutions," Electrochimica Acta, vol. 43, no. 19-20, pp. 28512861, 1998.

[40] B. Krishnamurthy, R. E. White, and H. J. Ploehn, "Nonequilibrium point defect model for time-dependent passivation of metal surfaces," Electrochimica Acta, vol. 46, no. 22, pp. 3387-3396, 2001.

[41] B. Krishnamurthy, R. E. White, and H. J. Ploehn, "Electric field strength effects on time-dependent passivation of metal surfaces," Electrochimica Acta, vol. 47, no. 15, pp. 2505-2513, 2002.

[42] B. Krishnamurthy, R. E. White, and H. J. Ploehn, "Simplified point defect model for growth of anodic passive films on iron," Electrochimica Acta, vol. 47, no. 20, pp. 3375-3381, 2002.

[43] L. F. Lin, C. Y. Chao, and D. D. Macdonald, "point defect model for anodic passive films," Journal of the Electrochemical Society, vol. 128, no. 6, pp. 1187-1194, 1981.

[44] L. F. Lin, C. Y. Chao, and D. D. Macdonald, "point defect model for anodic passive films. 2. Chemical Breakdown and Pit Initiation," Journal of the Electrochemical Society, vol. 128, no. 6, pp. 1194-1198, 1981.

[45] C. Y. Chao, L. F. Lin, and D. D. Macdonald, "point defect model for anodic passive films," pp. 1874-1879. 
[46] V. Maurice, W. P. Yang, and P. Marcus, "X-ray photoelectron spectroscopy and scanning tunneling microscopy study of passive films formed on (100) Fe-18Cr-13Ni single-crystal surfaces," Journal of the Electrochemical Society, vol. 145, no. 3, pp. 909-920, 1998.

[47] I. Olefjord and L. Wegrelius, "Surface analysis of passive state," Corrosion Science, vol. 31, pp. 89-98, 1990.

[48] B. Elsener and A. Rossi, "Effect of $\mathrm{pH}$ on electrochemical behaviour and passive film composition of stainless steels," Materials Science Forum, vol. 192, pp. 225-236, 1995.

[49] N. Hara and K. Sugimoto, "In situ analysis of passive films on Fe-Cr-Ni alloy by potential-modulated UV-visible reflection spectroscopy," Journal of the Electrochemical Society, vol. 138, no. 6, pp. 1594-1599, 1991.

[50] R. Kirchheim, B. Heine, H. Fischmeister, S. Hofmann, H. Knote, and U. Stolz, "The passivity of iron-chromium alloys," Corrosion Science, vol. 29, no. 7, pp. 899-917, 1989. 


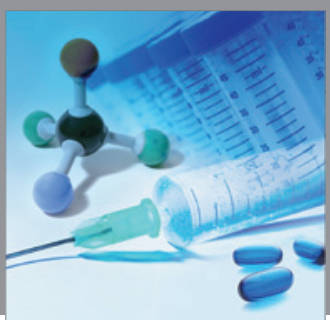

International Journal of

Medicinal Chemistry

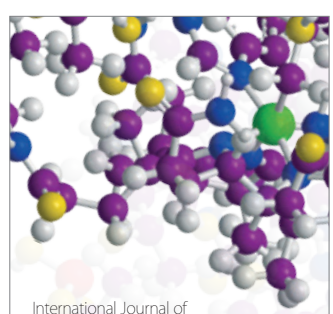

Carbohydrate Chemistry

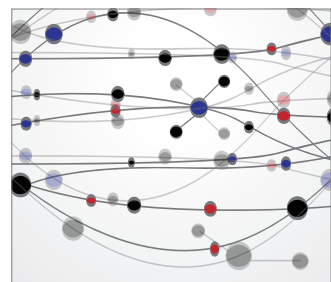

The Scientific World Journal
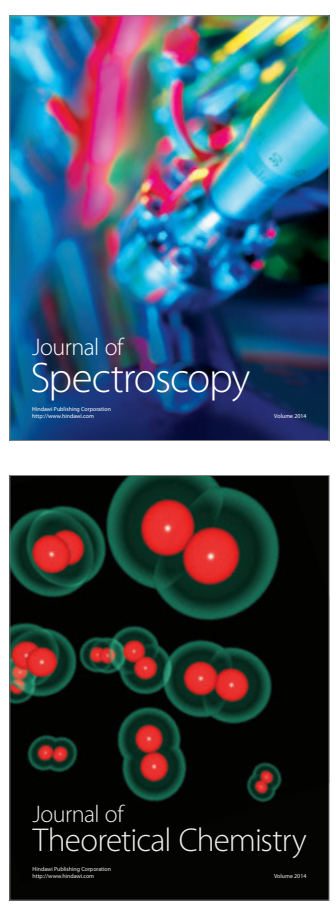
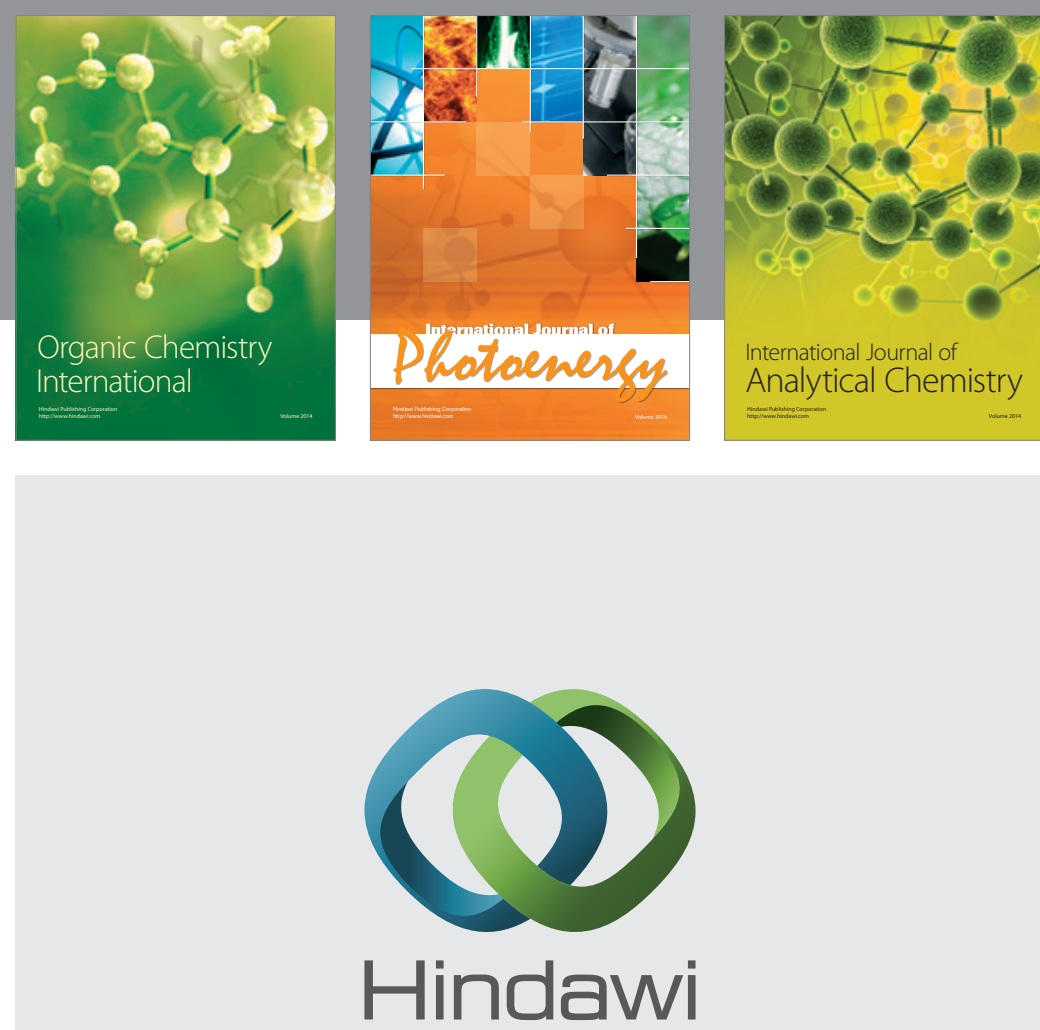

Submit your manuscripts at

http://www.hindawi.com
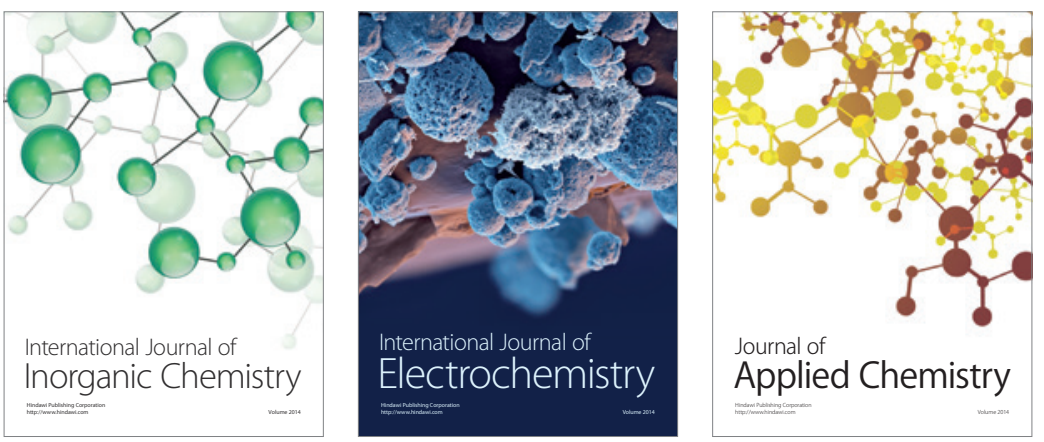

Journal of

Applied Chemistry
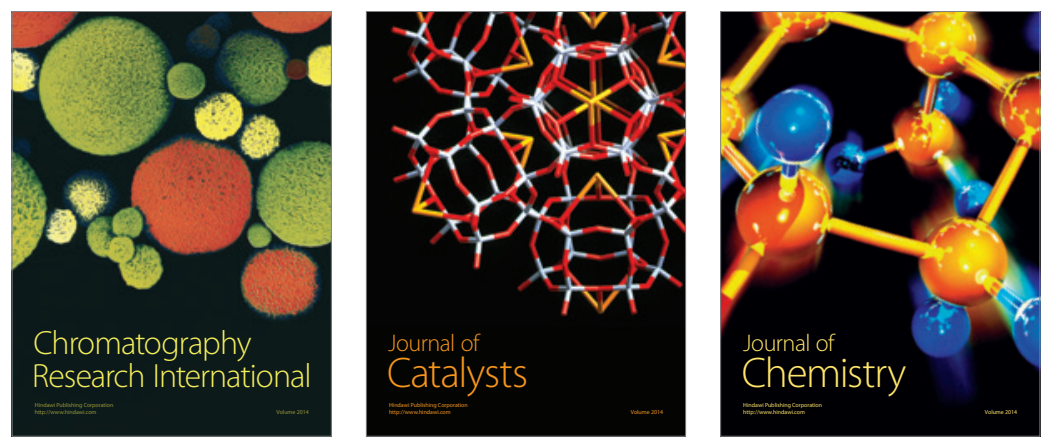
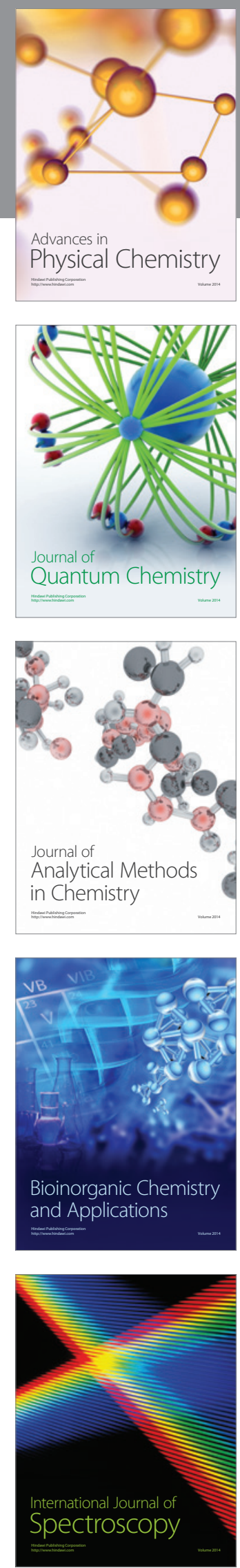